\title{
The project of insourcing before the project of outsourcing: extension of the De Boer's algorithm
}

\author{
Andrija Ražnatović \\ Faculty of Organizational Sciences \\ University of Belgrade \\ Belgrade, Serbia \\ raznatovic400216m@fon.bg.ac.rs
}

\author{
Prof. dr Mladen Čudanov \\ Faculty of Organizational Sciences \\ University of Belgrade \\ Belgrade, Serbia \\ mladenc@fon.bg.ac.rs
}

\author{
Prof. dr Ondrej Jaško \\ Faculty of Organizational Sciences \\ University of Belgrade \\ Belgrade, Serbia \\ jasko.ondrej@fon.bg.ac.rs
}

\begin{abstract}
Traditional approaches to outsourcing are commonly biased towards the outsourcing decision and consequently become a self-fulfilling prophecy. Departments destined for outsourcing are picked by management with prejudice as the least valuable with little or no regard to their features and place in the internal organizational network. Therefore, moving away from value chain to the analysis of relations between organizational units can aid managers better in the decision-making process. We propose extension of De Boer, Gaytan \& Arroyo algorithm. Our study is based on the in-depth study of organizational process, existing literature and specific case of outsourcing. Our conclusion is that the analysis of insourcing before the outsourcing decision is needed and we propose a set of questions before the outsourcing decision is made.
\end{abstract}

Keywords-outsourcing, management, organizational network, process, value chain

\section{INTRODUCTION}

Large multinational corporations (MNC) often reach for outsourcing as a quick solution for focusing on primary operations and cutting costs [1]. Naturally, due to their size, managers of big MNCs think that there is always room for cuts and they look for it at what is perceived to be the bottom of value chain. The result is a narrow and laser focus on outsourcing. However, not rarely, keeping costs down often turns out to be a low priority when all is said and done [2]. Before taking on outsourcing as a project, a closer look at organizational consequences must be taken.

Unless crisis management is in effect, organizational units should not be forcefully outsourced, and insourcing should remain an option. Insourcing is an investment while outsourcing is a shortcut, and shortcuts in business need to be approached carefully [3]. Many organizations just follow the trend and forget how complex a business strategy can be [4], and how different companies need different solutions. When treating outsourcing as a strategic project, instead of focusing on the bottom of value chain, the focus should be on organizational unit's effect on a particular organizational network, but above all on the existing intra-organizational network; because organizations do not consist of isolated individuals or groups making decisions and implementing them on their own [5].

\section{LITERATURE OVERVIEW}

First, we have analyzed seminal papers and books regarding the outsourcing scope. Bidwell's paper focuses on group interests and politics within one company and makes a point that these interests are often not for the benefit of the whole organization [2].

De Boer, Gaytan \& Arroyo satisficing model offers comprehensive and practical steps for the decision-making process [6]. It was used as a base to build upon and make a complete algorithm for evaluating key factors when faced with outsourcing. Our approach follows basic instruction given in the analysis of this article and extends the algorithm with the insourcing branch.

Kalis makes a very important, yet simple distinction between outsourcing, as a quick and quasi solution during dire times, and insourcing, as a way to foster and grow a company [3]. McDowell, Horn and Witkowski explain organizational network analysis and certain positions within the organization like central and peripheral nodes, and knowledge broker [7]. Pfeffer's book on how organizations are influenced and changed, and the importance of location in communication, is the forerunner in the area of the organizational network [5].

Another insight towards development of outsourcing algorithm is given in Jaško, Čudanov, Jevtić and Krivokapić in the chapter on outsourcing, and is used as a foundation for further research into this topic [8]. Methodical break down of McIvor's outsourcing framework is particularly good starting point for further research [9]. Sharp`s book provides information on advanced technology tools for workforce management and an analysis of the significance of the call centre to overall corporate strategies [10].

\section{RESEARCH METHODS}

An inductive study of a single organization was used to examine the organizational network`s influence on outsourcing decision. Using a single organization allowed better insight into internal organizational processes and interests and how they influenced the outsourcing process. 
However, other studies have used different settings in order to support the same or similar research. Teleco and Deutsche Bank reevaluated the significance of their IT departments and insourced them for better cohesiveness of key processes [11]. Dell decided to keep its call centre insourced in order not to sacrifice the efficiency of its operations [12]. US Airways also set up its own call centre following unsuccessful outsourcing [13].

Still, research limits imposed on the study were not negligible. Firstly, socio-economic conditions in which companies function are not the same and, therefore, specific situations cannot be generalized. But most of all, companies are not keen on revealing information regarding failed management attempts because of the negative effect on their reputation [14].

The specific setting for this study was the call centre of a petrol refining and distribution company "the petrol company". The petrol company is an MNC employing around 4,500 individuals, set in Serbia, a context of frontier emerging economy [15]. The call centre is employing 16 agents and the manager. The purpose of the call centre is to support buyers and end consumers and foster communication and exchange of information within the company [16].

\section{FINDINGS AND RESULTS}

The management of the petrol company believed that outsourcing the call centre seemed like a logical thing to do. After all, call centres have been the targets of many outsourcing projects in recent years [17]. However, not too far into the process, it became apparent that certain organizational features of the call centre (talent pool, external connections, security sensitivity, technology and multiple internal connections) positioned this organizational unit as the central node of the organizational network which made for a difficult decision [7].

\section{A. Talent Pool}

Most of the agents were college graduates who got the job through the "first chance" program. "First chance" program was designed to help recent college graduates, who have no work experience, to find employment. The petrol company was usually looking for graduates with high GPAs and other accomplishments because the "first chance" program was not only designed to benefit the young graduates, but the petrol company as well, and new talented employees would then be formed in accordance with the company`s needs. Indeed, call centre agents proved to be highly motivated and productive [18]. It was decided that the call centre would be the perfect place to start because that was the place where they would get a broad and basic practical knowledge of the company before moving onto other departments.

\section{B. External Connections}

The call centre provides a single contact for customers trying to reach the company through various points of access (phone, e-mail, web chat...) and it collects customer-related information into a central database [10].

The call centre also sells fuel cards and assists during transactions with corporate cards in matters such as authorization, PIN resetting, and non-approved refuelling.

Duties regarding external users are as follows [16]:

- Call centre acts as an intermediary between external users of services and representatives of organizational units (internal users, i.e. employees) in the Company.

- Call centre ensures receiving, recording, updating and forwarding of messages from external users to internal users.

- The call centre provides external users with information on card sales to corporate clients from the scope of Sales and Distribution.

- Through call centre, external users can give their recommendations, suggestions, remarks, objections, appeals and complaints regarding the quantity and quality of purchased goods and services rendered.

- Call centre takes part in monitoring the status of complaints by external users.

- $\quad$ The call centre provides information and assistance to external users at PS during transactions with corporate cards (authorization, PIN resetting, nonapproved refuelling) and with corporate and bank cards forgotten there.

- Call centre calls clients/potential clients and sells fuel cards by telephone /promotes products /services to potential/current buyers.

\section{Security Sensitivity}

Security is not taken lightly in the petrol company, and the call centre is no exception. From a security standpoint, call centres are one of the riskiest areas of any organization. By nature of their job, call centre employees have direct access to sensitive customer information. Also, they belong to entry-level and lowincome segment of employees. Another concern is the high turnover rate. So, you may have a large number of insiders who are more likely to need money and, hence, who may be comfortable with the idea of hurting their employer [19].

One of the duties of the call centre, when it comes to internal users, is recording information for HSE (Health, Safety and Environment) events. HSE function has a very important role in the company. Therefore, processing these events correctly is of the utmost importance. HSE events include work-related fatalities and injuries, employees working under the 
influence of alcohol, equipment and vehicle damages, oil spillages, refinery damages and malfunction, etc.

Because the call centre is involved in so many internal processes, allowing another company to have access to all this confidential information was potentially a nightmare for the security department. The worst-case scenario could be losing key competencies shared with the outsourcing partner [20].

\section{Technology updated}

One of the reasons for outsourcing is the possibility to access advanced technology [21]. However, the petrol company already purchased the modern CRM (Customer Relationship Management) software, as well as the state-of-the-art telephones and headphones.

Also, the call centre was equipped with the latest and more powerful desktop computers intended for the middle and top management, as well as the laptop computers in case the call centre had to function offsite. The management realized that agent's efficiency is driven by technology [22].

\section{E. Multiple internal connections}

This is the most important feature which trumps all the other. All organizations function beyond organization chart, there are informal teams, and they rely on that one person or group who always knows what you need. These critically important connections are the lifeblood of organizations [7]

Various business processes of the petrol company flow through the call centre and here is the list of departments on whose behalf the call centre performs certain activities [16]:

- Document Management Department

- Retail Department, Sales and Distribution

- Wholesale Department, Sales and Distribution

- Marketing Department

- Department for Internal Communication

- HSE Function

- HSE Organizational Units in Blocks

- Business Centre Department

- IT Department

- Business Development Department

- Department for Corporate Security

- Centre for Joint HR Services

- Department for Development and Capital Construction

Last, but not the least, was the integration of the call centre into the crisis management group. Another realization by the management, that during crisis time there is a great need for handling internal and external input and inquiries, helped solidify call centre`s position as a central node in the organizational network.

\section{EXTENSION OF DE BOER'S ALGORITHM WITH INSOURCING}

In theory, outsourcing decision revolves around the concept of core competencies and value chain analysis. The perfect example of a general concept is McIvor`s framework which starts with the defining core activities and evaluating them within the value chain and then moves onto cost analysis [8]. However, defining core activities is not as easy as it seems and cost-cutting single-mindedness can put the outsourcing decision on the wrong track [23]. Values held within the company can also influence the decision, as this is in essence organizational change [24]. Even McIvor is aware of this drawback and in his last phase talks about analysis of relations between organizational units [9].

If observing outsourcing models with more detail, two types of outsourcing models can be identified. First, models which suggest a top-down analysis of processes in order to choose the activity to outsource; and second, outsourcing models that assume that particular activity is already identified [6].

Satisficing model tries to achieve and avoid the trap of pre-identifying organizational unit to be outsourced [6]. However, it does not leave any room for the option of insourcing in order to have an allinclusive model.

Insourcing has been increasingly regarded as the alternative to outsourcing, especially offshore, and there are examples of successful insourcing after failed outsourcing attempts [25,26,27]. Generally, insourcing is regarded as a viable alternative, even in the beginning $[28,29]$. Ignoring the outsourcing potential, in the beginning, can incur major costs for the enterprise and cause all the problems related to outsourcing.

Common mistakes regarding outsourcing are identified by Barthelemy [14] as:

- poor judgment should the activity have been initially outsourced (which is partially covered in the original algorithm and extended by our proposal);

- orientation towards the wrong outsource to supply services / products;

- lack of understanding and agreement among the outsourcer / outsource and other involved participants;

- not enough discussion on personal issues;

- lack of control of the overview of the outsourcing process;

- failing to perceive outsourcing hidden costs;

- lack of the exit strategy for a specific contracted outsourcing agreement. 
Therefore, in order not to make the mistake of outsourcing for the sake of outsourcing, the possibility of insourcing is added. This insourcing detour in the model contains all the key organizational unit features mentioned above, which influence the organizational network.

Our extension of the algorithm is given in appendix 1. It is based on five questions:

- Does the process have multiple internal connections, sufficient to justify the insourcing decisions?

- Do we have available resources, especially talents, on the internal pool of resources?

- Are there existing external connections within the organizational network?

- Is the process related to security-sensitive issues?

- Are there issues related to the update of technology?

Each of those factors, or the combination of them, can qualify the process for the insourcing. The order of checking is also important because most important issues should be checked as first in order.

\section{CONCLUSION}

Our paper extends research on outsourcing by trying to identify descriptive attributes of an organizational unit which can make or break the organizational network. Using a case study methodology, we analyzed the process followed by a petrol company to outsource its call centre. The case study method is advocated in the social sciences [30,31], and although it has limitation in generalization, it can offer deeper insights into relationships of complex social systems.

The results show that pre-identifying organizational unit to be outsourced can lead to process fragmentation and organizational network break-down. Therefore, insourcing should be made available. In order to make a visual path for decisionmakers to follow, we used the Satisficing model [6] and added the insourcing path which can bring us back to outsourcing part if certain criteria are not met.

\section{REFERENCES}

[1] C. Kahraman, O. Engin, O. Kabak and I. Kaya, "Information systems outsourcing decisions using a group decision-making approach," Engineering Applications of Artificial Intelligence, vol. 22, iss. 6, September 2009, pp. 2-3. doi: 10.1016/j.engappai.2008.10.009

[2] M. J. Bidwell, Politics and Firm Boundaries: How Organizational Structure, Group Interests, and Resources Affect Outsourcing," Organization Science, vol. 23, iss. 6, 2012, pp. 4-11. doi: 10.1287/orsc.1120.0772

[3] M. Kalis, "Outsourcing Is a Shortcut; Insourcing Is an Investment," Entrepreneur.com, April 2018.

[4] M. Power, C. Bonifazi and K. C. Desouza, "Ten outsourcing traps to avoid," Journal of Business Srtategy, vol. 25, no. 2, April 2004, pp. 37-42. doi: 10.1108/02756660410525399
[5] J. Pfeffer, Managing with Power: Politics and Influence in Organizations. Boston, MA: Harvard Business School Press, 1992, pp. 207.

[6] L. de Boer, J. Gaytan and P. Arroyo, "A satisficing model of outsourcing," Supply Chain Management: An International Journal, vol. 11, iss. 5, 2006, pp. 444-455. doi: $10.1108 / 13598540610682462$

[7] T. McDowell, H. Horn and D. Witkowski, Organizational Network Analysis, Deloitte Development LLC, 2016.

[8] O. Jaško, M. Čudanov, M. Jevtić and J. Krivokapić, "Organizational design: approaches, methods and models" [Organizacioni dizajn: pristupi, metode i modeli], Smederevo: Newpress, 2017, pp. 376-379.

[9] R. McIvor, "A practical framework for understanding the outsourcing process," Supply Chain Management: An International Journal, vol. 5, iss. 1, 2000, pp. 22-36.

[10] D. Sharp, Call Centre Operation: Design, Operation and Maintenance. Burlington, MA: Elsevier Science, 2003, pp. 45

[11] F. Law, "Breaking the outsourcing path: Backsourcing process and outsourcing lock-in," European Management Journal, 2017.

[12] A. McCue, "For Dell, Indian call centre failure a lesson," Silicon.com, March 2004

[13] B. Audrey, "Companies Shifting Call Centre Services InHouse,” Infinitcontact.com, January 2011.

[14] J. Barthelemy, "The seven deadly sins of outsourcing," Academy of Management Executive, vol. 17, no. 2, 2003, pp. 87-98.

[15] S. Jednak, "Emerging Economies Development: BRICS vs East European Countries," European Project Management Journal, vol. 7 iss. 1, December 2017, pp. 36-47.

[16] I. Marić, Instruction for Operations, Call Centre NIS j.s.c. Novi Sad, 2013

[17] Y. Xia, B. Chen, V. Jayaraman and C. L. Munson, "Competition and market segmentation of the call centre service supply chain," European Journal of Operational Research, vol. 21, no. 15, July 2015 , pp. 1. doi:10.1016/j.ejor.2015.06.027

[18] C. M. Wallace, R. Waldersee and G. Eagleson, "The Sacrificial HR Strategy in Call Centres," International Journal of Service Industry Management, vol. 11, no. 2, May 2000, pp. 14-15. doi: 10.1108/09564230010323741

[19] M. Tupia, "Information security risks in a customer service call centre infrastructure," Guidelines for security managers, presented at International Conference on Networked Computing and Advanced Information Management, Seoul, Korea, August 2010.

[20] G. Nassimbeni, M. Sartor and D. Dus, "Security risks in service offshoring and outsourcing," Industrial Management \& Data Systems, vol. 112, iss. 3, 2012, pp. 405-440. doi: $10.1108 / 02635571211210059$

[21] R. Gonzalez, J. Gasco and J. Llopis, "Information systems outsourcing reasons and risks: a new assesment," Industrial Management \& Data Systems, vol. 110, iss. 2, 2010, pp.4-6. doi: $10.1108 / 02635571011020359$

[22] C. M. Wallace, R. Waldersee and G. K. Eagleson, "The Sacrificial HR Strategy in Call Centres," International Journal of Service Industry Management, vol. 11, no. 2, May 2000, pp. 14-15. doi: 10.1108/09564230010323741

[23] N. Popović, O. Jaško and S. Prokić, "Menadžment interorganizacionih odnosa" [Management of interorganizational relations]. Smederevo: Newpress, 2010, pp. 68-74.

[24] N. Janićijević, "Contradictory values in the process of organizational change: a case study," Management: Journal of Sustainable Business and Management Solutions in Emerging Economies, vol. 22 iss. 2, 2017, pp. 29-36. doi:10.7595/management.fon.2017.0009

[25] J. S. Arlbjørn and O. S. Mikkelsen, "Backshoring manufacturing: Notes on an important but under-researched 
theme," Journal of Purchasing and Supply Management, vol. 20, no. 1,2015 , pp. 60-62.

[26] N. B. Moe and G. K. Hanssen, "From offshore outsourcing to offshore insourcing: Three stories," IEEE Seventh International Conference on Global Software Engineering, pp. $1-10,2012$.

[27] N. B. Moe, D. Šmite, G. K. Hanssen and H. Barney, "From offshore outsourcing to insourcing and partnerships: four failed outsourcing attempts," Empir Software Eng, vol. 19, pp 1225, 2014. doi: 10.1007/s10664-013-9272-x
[28] P.V. Freytag, A.H. Clarke and M.R. Evald, "Reconsidering outsourcing solutions," European Management Journal, vol. 30, no. 2, 2012, pp. 99-110.

[29] I. Oshri, J. Kotlarsky, and L.P. Willcocks, The Handbook of Global Outsourcing and Offshoring, 3rd Edition, Springer: Germany, 2015.

[30] J.R. Feagin, A.M. Orum, and G. Sjoberg. A case for the case study. UNC Press Books, 1991.

[31] A. Orum. "Case Study: Logic." in NJ. Smelser and P. Baltes (eds) International Encyclopedia of the Social and Behavioral Sciences. Amsterdam, The Netherlands: Elsevier. pp. 15091513 . 


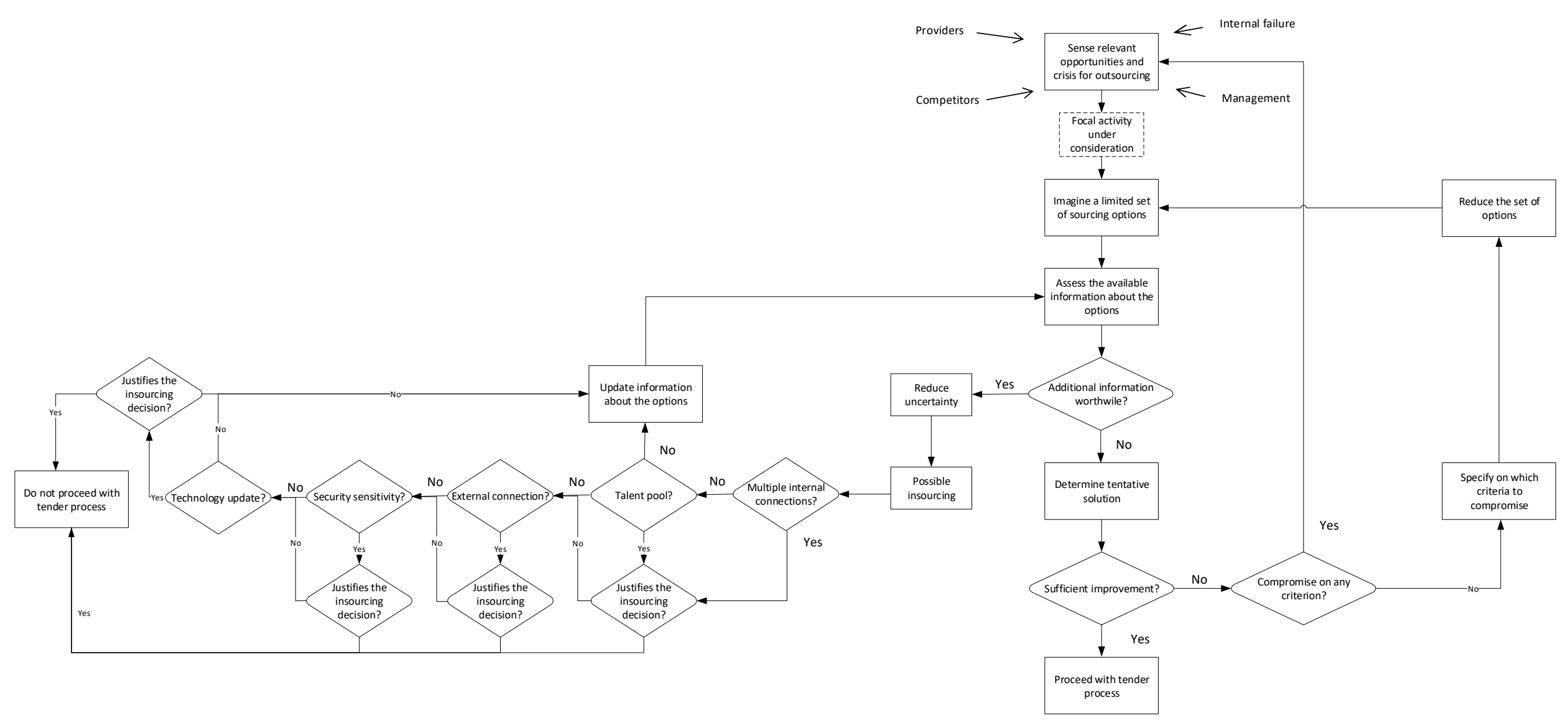

